ECOLOGICA, Vol. 28, No 102 (2021), 309-314

https://doi.org/10.18485/ecologica.2021.28.102.24

Originalni naučni rad

UDC: 669.14 .018 .18

\title{
Ekstrakt ruzmarina kao ekološki inhibitor korozije bakra u hloridnoj sredini
}

\section{Rosemary extract as an ecological inhibitor of copper corrosion in chloride medium}

\author{
Vesna Grekulović ${ }^{1 *}$, Nada Štrbac ${ }^{2}$, Aleksandra Mitovski $^{3}$ \\ 1,2,3Univerzitet u Beogradu, Tehnički fakultet u Boru, VJ 12, Bor, Srbija / \\ University of Belgrade, Technical Faculty in Bor, VJ 12, Bor, Serbia \\ *Autor za prepisku / Corresponding author
}

Rad primljen / Received: 14.12.2020, Rad prihvaćen / Accepted: 10.05.2021.

Sažetak: Zbog široke primene bakra od velikog značaja je elektrohemijsko ispitivanje bakra u različitim sredinama. lako je bakar otporan na uticaj atmosfere i mnogih hemikalija, ipak podleže koroziji u agresivnim sredinama. Toksičnost mnogobrojnih inhibitora korozije bakra dovela je do smanjivanja ili potpunog prestanka njihove upotrebe kao inhibitora korozije. U ovom radu je ispitivana mogućnost primene ekstrakta ruzmarina kao ekološkog inhibitora korozije bakra u hloridnoj sredini. Elektrohemijsko ponašanje bakra u $0,5 \mathrm{~mol} / \mathrm{dm}^{3} \mathrm{NaCl}$ u odsustvu i prisustvu ekstrakta ruzmarina različitih koncentracija ispitivano je metodom merenja potencijala otvorenog kola, metodom ciklične voltametrije i potenciostatskom metodom. Rezultati merenja potencijala otvorenog kola pokazuju da su vrednosti potencijala otvorenog kola u prisustvu ekstrakta ruzmarina pozitivnije u odnosu na vrednost potencijala otvorenog kola bez prisustva ekstrakta ruzmarina. Na anodnim polarizacionim krivama se pojavljuju tri strujna pika koji odgovaraju formiranju hlorida bakra i oksida bakra. Vrednost jačine struje strujnih pikova opada sa povećanjem koncentracije ekstrakta ruzmarina u elektrolitu, što ukazuje na inhibitorsko dejstvo ekstrakta ruzmarina. Rezultati potenciostatskog merenja pokazuju da se stabilizacija brže dostiže u prisustvu ekstrakta ruzmarina. Vrednosti stacionarne jačine struje u $0,5 \mathrm{~mol} / \mathrm{dm}^{3} \mathrm{NaCl}$ u prisustvu ekstrakta ruzmarina niže su u odnosu na stacionarnu vrednost jačine struje bez prisustva ekstrakta. Prisustvo ekstrakta ruzmarina dovodi do formiranja zaštitnog filma na površini bakra, koji usporava proces oksidacije bakra. Mikrofotografije površine bakra nakon potenciostatskog tretiranja bakra u $0,5 \mathrm{~mol} / \mathrm{dm}^{3} \mathrm{NaCl}$ bez i u prisustvu ekstrakta ruzmarina pokazuju da je površina bakra značajno oštećena nakon potenciostatskog tretiranja u $0,5 \mathrm{~mol} / \mathrm{dm}^{3} \mathrm{NaCl}$. Pri dodatku ekstrakta ruzmarina oštećenja na površini bakra su manja usled formiranja zaštitnog filma na površini bakra i, sledstveno tome, inhibitorskog dejstva ekstrakta ruzmarina.

Ključne reči: bakar, elektrohemijsko ponašanje, hloridna sredina, ekstrakt ruzmarina.

Abstract: Due to widespread copper usage, electrochemical investigation of copper in different media is of a great
importance. Although copper is resistant to the atmosphere influence and the impact of many chemicals, it is still
resistless to corrosion in aggressive environments. Toxicity of many copper corrosion inhibitors led to reduction or
complete cutoff of their use as corrosion inhibitors. Possibility for using rosemary extract as an ecological inhibitor of
copper corrosion in a chloride media was investigated in this paper. Electrochemical behavior of copper in 0.5
$\mathrm{~mol} / \mathrm{dm}^{3} \mathrm{NaCl}$ in the absence and in the presence of rosemary extract in different concentrations was investigated
by method of open circuit potential measurement, cyclic voltammetry method and potentiostatic method. Results of
measuring the open circuit potential show that the values of the open circuit potential in the presence of rosemary
extract are more positive in relation to the value of the open circuit potential in the absence of rosemary extract.
Three current peaks appear on the anode polarization curves, which correspond to copper chloride and copper
oxide formation. Current intensity value of current peaks decreases with increasing concentration of rosemary extract
in the electrolyte, which indicates the inhibitory effect of rosemary extract. Results of potentiostatic measurements
show that stabilization is achieved faster in the presence of rosemary extract. Values of the stationary current 
intensity in $0.5 \mathrm{~mol} / \mathrm{dm}^{3} \mathrm{NaCl}$ in the presence of rosemary extract are lower in relation to the value of the current intensity in the absence of the extract. Presence of rosemary extract leads to formation of a protective film on copper surface, which decelerates the oxidation process of copper. Microphotographs of the copper surface after potentiostatic treatment of copper in $0.5 \mathrm{~mol} / \mathrm{dm}^{3} \mathrm{NaCl}$, without and in the presence of rosemary extract, show significantly damaged copper surface after potentiostatic treatment in $0.5 \mathrm{~mol} / \mathrm{dm}^{3} \mathrm{NaCl}$. The addition of rosemary extract damages the copper surface in the lesser extent, due to forming a protective film on the copper surface and, consequently, the inhibitory effect of rosemary extract.

Keywords: copper, electrochemical behavior, chloride medium, rosemary extract.

\footnotetext{
${ }^{1}$ orcid.org/0000-0001-6871-4016, e-mail: vgrekulovic@tfbor.bg.ac.rs

${ }^{2}$ orcid.org/0000-0003-4836-1350, e-mail: nstrbac@tfbor.bg.ac.rs

3orcid.org/0000-0002-9130-2076, e-mail: amitovski@tfbor.bg.ac.rs
}

\section{UVOD / INTRODUCTION}

Korozija metala i legura predstavlja veliki problem za industriju i privredu jer dovodi do značajnih materijalnih i novčanih gubitaka. U cilju zaštite metalnih materijala od korozije važno je ispitivanje uticaja različitih potencijalnih inhibitora u različitim sredinama. Do danas je ispitan veliki broj mogućih inhibitora bakra. Jedan od njih je benzotriazol koji se pokazao kao dobar inhibitor korozije bakra, ali je toksičan (Hazzazi, 2007; Kosec i dr., 2007; Milić, Antonijević, 2009; Milošev i dr., 2013; Petrović Mihajlović, Antonijević, 2009; Toumiat et al., 2017).

Istraživanja treba usmeriti ka primeni ekoloških inhibitora, kod kojih se kao ključni kriterijum za primenu postavlja njihova ekološka prihvatljivost. Istraživanje ekstrakata biljaka u zadnje vreme je područje velikog interesovanja brojnih autora kada je reč o inhibitorima korozije. Zeleni inhibitori predstavljaju skup jedinjenja koja mogu da budu životinjskog ili biljnog porekla. Pored toga što su biorazgradivi, ne sadrže teške metale, što in čini ekološki prihvatljivima. Inhibitorske ekstrakte najčešće čini mešavina jedinjenja koja sadrže kiseonik, sumpor i vodonik. Oni su i prirodni antioksidansi, jeftini su i ne štete okolini. Biljni ekstrakti se smatraju izvorom prirodno sintetizovanih jedinjenja koji su ekološki prihvatljivi, netoksični i mogu se ekstrahovati jednostavnim i jeftinim postupcima. Ekstrakti dobijeni od korena biljaka, semena, lišća, stabljika, cveta i voća mogu se koristiti kao inhibitori korozije metala i legura u različitim sredinama (Coulibaly et al., 2018; Emad, AL-Rasheedi, 2015; ElAziz et al., 2018; Fouda et al., 2014; Fouda et al., 2015; Gudić i dr., 2014; Ivanov i dr., 2020; Jokar et al., 2016; Kesavan et al., 2012; Mounir et al., 2015; Raja, Sethraman, 2008; Radošević, 2012; Rajčić Vujasinović i dr., 2016).

U ovom radu su prikazani rezultati ispitivanja uticaja dodatka ekstrakta ruzmarina na koroziono ponašanje bakra u $0,5 \mathrm{~mol} / \mathrm{dm}^{3} \mathrm{NaCl}$.

\section{MATERIJALI I METODE / MATERIALS AND METHODS}

Uticaj ekstrakta ruzmarina na koroziono ponašanje bakra u $0,5 \mathrm{~mol} / \mathrm{dm}^{3} \mathrm{NaCl}$ ispitivan je na sistemu koji se sastoji od:

- elektrohemijske ćelije sa tri elektrode: radna elektroda - bakarna žica dobijena Dip-forming postupkom, pri čemu radnu površinu elektrode predstavlja poprečni presek žice površine $0,07 \mathrm{~cm}^{2}$, referentna elektroda - zasićena kalomelova elektroda (ZKE), pomoćna elektroda - platinska elektroda (platinski lim dimenzija $1 \mathrm{~cm} \times 2 \mathrm{~cm}$ ).

- hardvera (PC, AD/DA konvertor PCl-20428 W proizveden od strane Burr-Brown-a i analogni interfejs razvijen na Tehičkom fakultetu u Boru) (Stević, Rajčić Vujasinović, 2007),

- softvera za merenje i upravljanje (LabVIEW 6 platforma i specijalno razvijena aplikacija za elektrohemijska merenja).

Potencijal otvorenog kola meren je u odnosu na zasićenu kalomelovu elektrodu u trajanju od 60 sekundi, snimanje anodnih polarizacionih krivih vršeno je $\mathrm{u}$ opsegu potencijala od $-0,4 \mathrm{~V}$ vs. ZKE do $1 \mathrm{~V} \mathrm{u}$ odnosu na ZKE brzinom promene potencijala od 20 $\mathrm{mV} / \mathrm{s}$ i potenciostatske krive su snimane na $0,05 \mathrm{~V}$ u odnosu na ZKE u trajanju od $100 \mathrm{~s}$ i temperaturi od $25^{\circ} \mathrm{C}$. Karakterizacija površine elektrode nakon potenciostatskog tretiranja je vršena optičkom mikroskopijom.

Supstance korišćene za pripremu radnih rastvora su: $\mathrm{NaCl}$ p.a. čistoće proizvođača d.d. "Zorka Pharma" Šabac, usitnjen svež ruzmarin, $96 \%$ etanol proizvođača d.d. "Zorka Pharma" Šabac i destilovana voda. Ekstrakt ruzmarina pripremljen je na sledeći način: usitnjenih $20 \mathrm{~g}$ ruzmarina stavljeno je u $200 \mathrm{~mL} 96$ \% etanola. Nakon 2 meseca stajanja u etanolu vrši se filtriranje. Dobijeni ekstrakt se čuva u frižideru. 


\section{REZULTATI I DISKUSIJA /} RESULTS AND DISCUSSION

Rezultati merenja potencijala otvorenog kola za bakar u $0,5 \mathrm{~mol} / \mathrm{dm}^{3} \mathrm{NaCl}$ bez i uz dodatak ekstrakta ruzmarina prikazani su na slici 1 .

Sa grafika se vidi da potencijal otvorenog kola za bakar u 0,5 mol/dm³ $\mathrm{NaCl}$ iznosi $\mathrm{E}=-0,310 \mathrm{~V}$ vs.
ZKE. Sa dodatkom etanolskog ekstrakta ruzmarina u $0,5 \mathrm{~mol} / \mathrm{dm}^{3} \mathrm{NaCl}$ potencijal otvorenog kola je pozitivniji nego bez dodatka ekstrakta ruzmarina. Sa dodatkom $1 \mathrm{~mL}$ i $2 \mathrm{~mL}$ ekstrakta ruzmarina potencijal otvorenog kola iznosi oko - 0,19 V vs. ZKE, dok sa dodatkom $3 \mathrm{~mL}$ i $4 \mathrm{~mL}$ ekstrakta ruzmarina oko $0,154 \mathrm{~V}$ vs. ZKE.

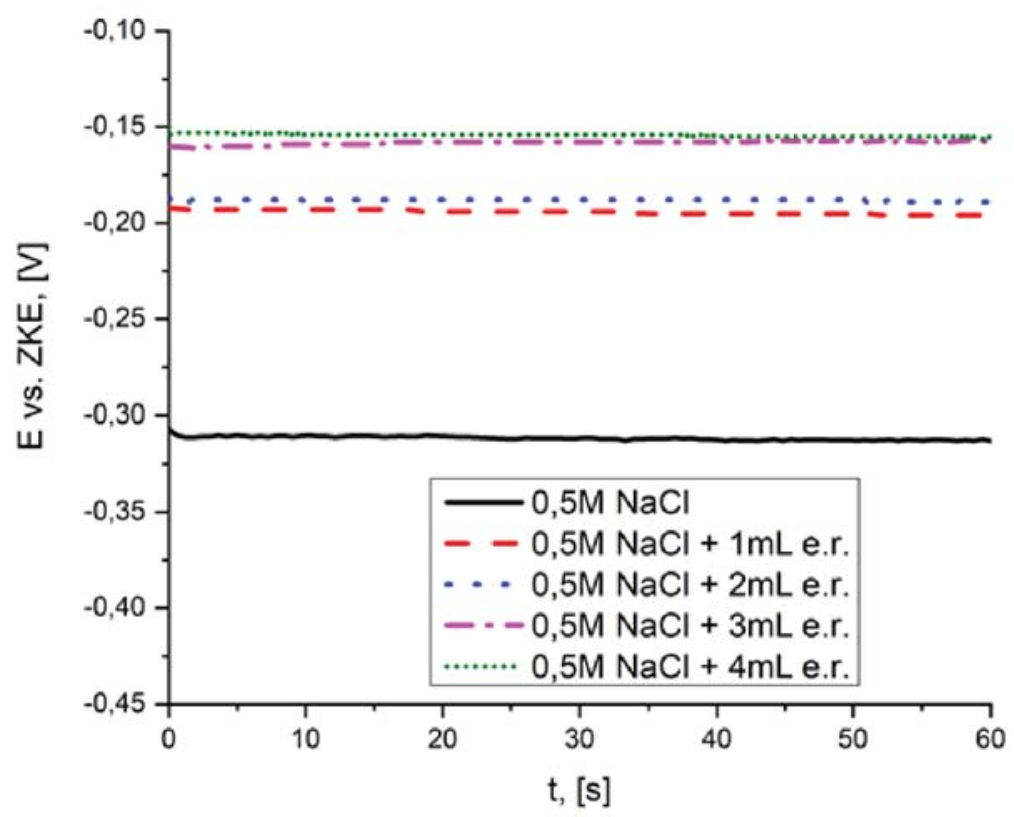

Slika 1 - Potencijal otvorenog kola za čist bakar u 0,5 mol/dm ${ }^{3} \mathrm{NaCl}$ sa i bez dodatka ekstrakta ruzmarina (e.r.) Figure 1 - Open circuit potential of copper in $0.5 \mathrm{~mol} / \mathrm{dm}^{3} \mathrm{NaCl}$, with and without the addition of rosemary extract (e.r.)

Na slici 2 su prikazane anodne polarizacione krive snimljene za čist bakar u rastvoru $0,5 \mathrm{~mol} / \mathrm{dm}^{3}$ $\mathrm{NaCl}$, bez i u prisustvu ekstrakta ruzmarina.

Anodne polarizacione krive su snimane brzinom promene potencijala od $20 \mathrm{mV} / \mathrm{s}$ u oblasti potencijala od $-0,4 \mathrm{~V}$ vs. ZKE do $1,0 \mathrm{~V}$ vs. ZKE. Na anodnoj polarizacionoj krivoj dobijenoj u $0,5 \mathrm{~mol} / \mathrm{dm}^{3} \mathrm{NaCl}$ pojavljuju se tri strujna pika koji odgovaraju procesu oksidacije, to jest korozije bakra.

Strujni pikovi $A_{1}$ i $A_{2}$ odgovaraju formiranju hlorida bakra po sledećem mehanizmu (Kosec i dr., 2007; Milošev i dr., 2013; Toumiat et al., 2017):

$$
\begin{aligned}
& \mathrm{Cu}+\mathrm{Cl}^{-}=\mathrm{CuCl}_{\text {ads }}+\mathrm{e}^{-} \\
& \mathrm{CuCl} \text { ads }+\mathrm{Cl}^{-}=\mathrm{CuCl}_{2}^{-} \\
& \mathrm{Cu}+\mathrm{CuCl}_{2}=2 \mathrm{CuCl}+\mathrm{e}^{-}
\end{aligned}
$$

Strujni pik $A_{3}$ odgovara formiranju oksida bakra $\mathrm{Cu}_{2} \mathrm{O}$ po sledećoj jednačini (Kosec i dr., 2007):

$$
2 \mathrm{CuCl}+2 \mathrm{OH}^{-}=\mathrm{Cu}_{2} \mathrm{O}+2 \mathrm{Cl}^{-}+\mathrm{H}_{2} \mathrm{O}
$$

Upoređujući anodne polarizacione krive za bakar dobijene u prisustvu ekstrakta ruzmarina sa anodnom polarizacionom krivom bez prisustva ekstrakta ruzmarina, uočava se da su vrednosti jačine struje pri svim dodacima ekstrakta ruzmarina niže u odnosu na vrednosti jačine struje bez prisustva ekstrakta ruzmarina. Rezultati dobijeni metodom ciklične voltametrije ukazuju na to da ekstrakt ruzmarina deluje kao anodni inhibitor korozije bakra u $0,5 \mathrm{~mol} / \mathrm{dm}^{3}$ $\mathrm{NaCl} i$ to izraženije $u$ oblasti potencijala $u$ kojoj se pojavljuju strujni pikovi $A_{2}$ i $A_{3}$.

Potenciostatska ispitivanja u prisustvu ekstrakta ruzmarina vršena su na potencijalu od $0,05 \mathrm{~V}$ vs. ZKE u trajanju $100 \mathrm{~s}$. Na slici 3 prikazane su potenciostatske krive nakon potenciostatskog tretiranja bakra tokom $100 \mathrm{~s} \mathrm{u} 0,5 \mathrm{~mol} / \mathrm{dm}^{3} \mathrm{NaCl}$ bez i sa dodatkom ekstrakta ruzmarina. Sa slike se vidi da jačina struje za bakar u $0,5 \mathrm{~mol} / \mathrm{dm}^{3} \mathrm{NaCl}$ bez dodatka ekstrakta naglo opada u prvih $5 \mathrm{~s}$, zatim raste do oko $20 \mathrm{~s}$, nakon čega ponovo blago opada, da bi se zatim lagano stabilizovala i dostigla stacionarno stanje. Sa dodatkom ekstrakta ruzmarina od $1 \mathrm{~mL}, 2 \mathrm{~mL}, 3$ $\mathrm{mL}$ i $4 \mathrm{~mL}$ jačina struje na početku naglo opada nakon čega se stabilizuje. Vrednosti stacionarne jačine struje u $0,5 \mathrm{~mol} / \mathrm{dm}^{3} \mathrm{NaCl}$ u prisustvu ekstrakta ruzmarina niže su u odnosu na stacionarnu vrednost jačine struje bez prisustva ekstrakta. Stacionarna jačina struje je najniža sa dodatkom ekstrakta ruz- 
marina od $4 \mathrm{~mL}$. Na površini bakra u prisustvu ekstrakta ruzmarina dolazi do formiranja zaštitnog filma i stabilizacija jačine struje se brže postiže u prisustvu ekstrakta ruzmarina.

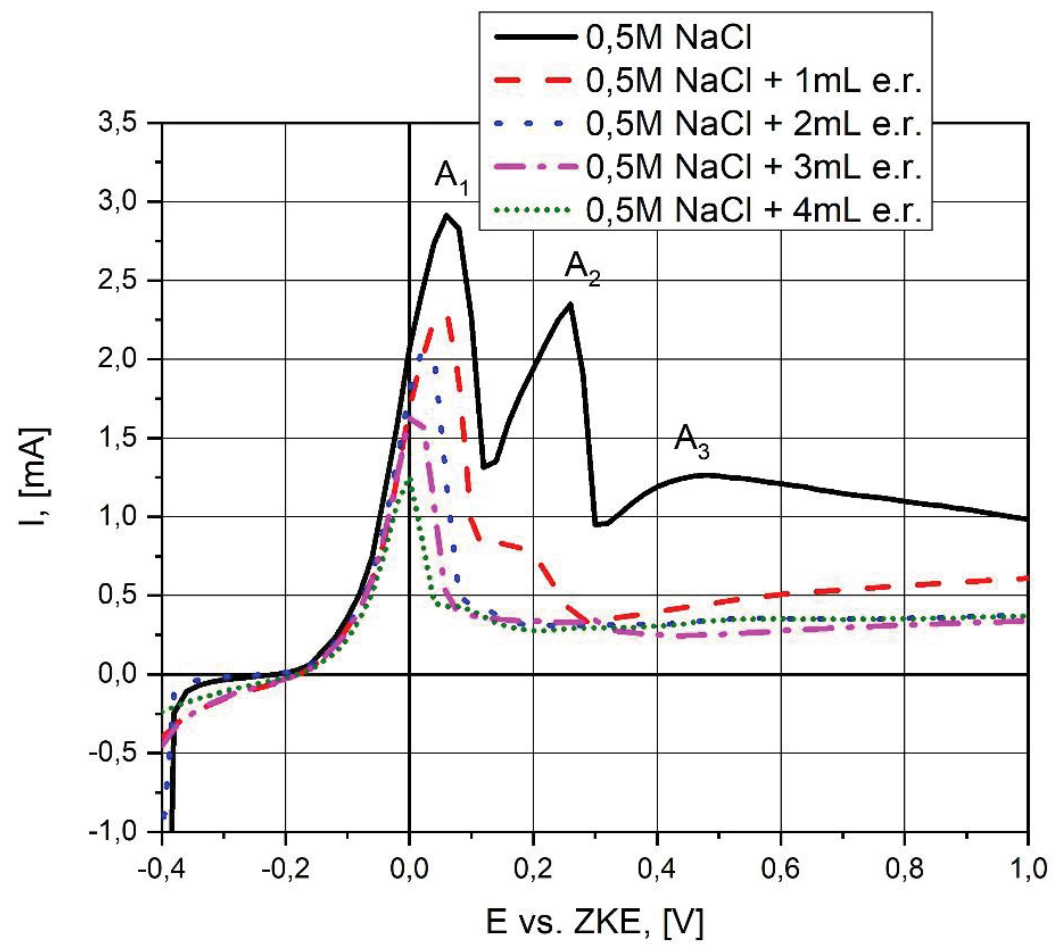

Slika 2 - Anodne polarizacione krive za čist bakar u 0,5 mol/dm ${ }^{3} \mathrm{NaCl}$ sa i bez dodatka ekstrakta ruzmarina (e.r.); brzina promene potencijala $20 \mathrm{mV} / \mathrm{s}$

Figure 2 - Anodic polarisation curves for pure copper in $0.5 \mathrm{~mol} / \mathrm{dm}^{3} \mathrm{NaCl}$, with and without the addition of rosemary extract (e.r.); scan rate $20 \mathrm{mV} / \mathrm{s}$

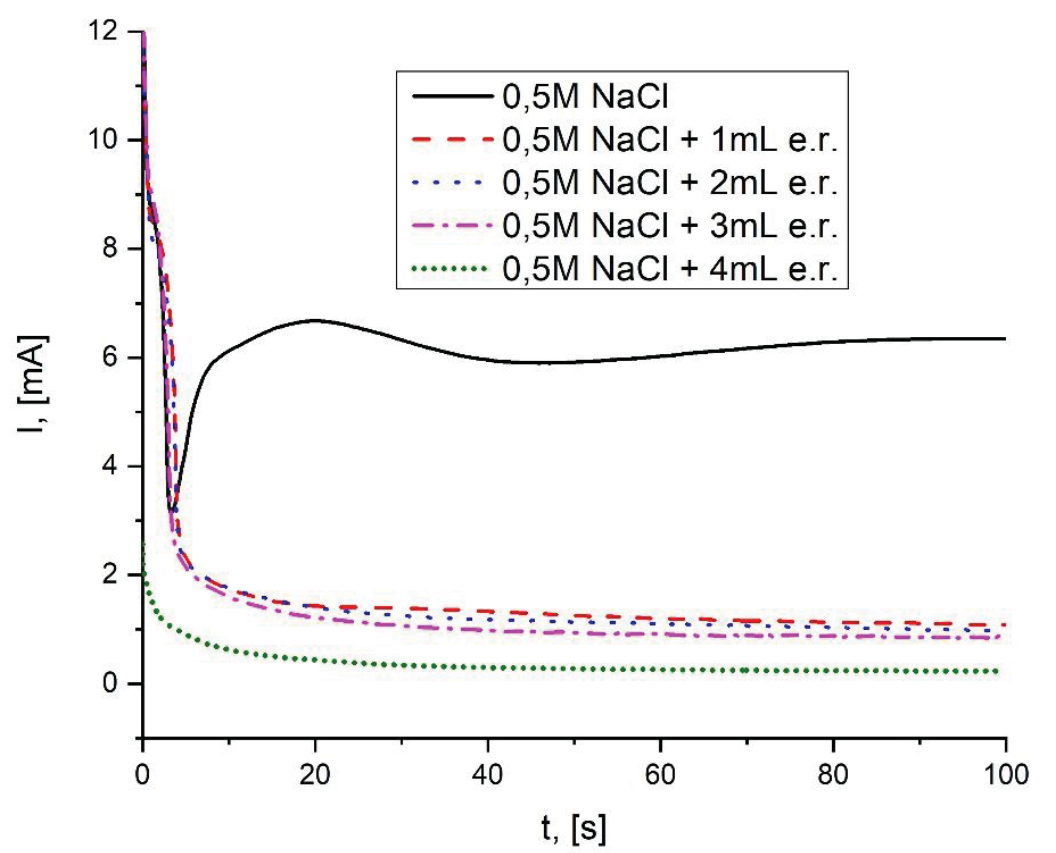

Slika 3 - Potenciostatske krive za bakar u 0,5 mol/dm ${ }^{3} \mathrm{NaCl}$, bez i uz dodatak ekstrakta ruzmarina (e.r.) na potencijalu od $0,05 \mathrm{~V}$ vs. ZKE

Figure 3 - Potentiostatic curves for the copper in $0.5 \mathrm{~mol} / \mathrm{dm}^{3} \mathrm{NaCl}$, with and without the addition of rosemary extract (e.r.), at the potential of $0,05 \mathrm{~V}$ vs. SCE 
Nakon potenciostatskog tretiranja bakra $u$ prisustvu i odsustvu ekstrakta ruzmarina vršena je karakterizacija površine bakra optičkom mikroskopijom. Na slici 4a prikazana je mikrofotografija netretiranog bakra, dok su na slikama 4b-4f prikazane mikrofotografije površine bakra nakon potenciostatskog tretiranja u rastvoru $0,5 \mathrm{~mol} / \mathrm{dm}^{3} \mathrm{NaCl}$ bez i sa dodatkom ekstrakta ruzmarina. Na slici 4b prikazana je mikrofotografija površine bakra nakon potencio- statskog tretiranja u $0,5 \mathrm{~mol} / \mathrm{dm}^{3} \mathrm{NaCl}$, gde se jasno vidi da je površina znatno oštećena. Pri dodatku $1 \mathrm{~mL}$ etanolskog ekstrakta ruzmarina na površini bakra dolazi do formiranja zaštitnog sloja i javljaju se manja oštećenja, što se vidi na slici 4c. Na slikama $4 \mathrm{~d}-4 \mathrm{f}$ se uočava da se sa povećanjem zapremine ekstrakta ruzmarina javljaju sve manja oštećenja na površini bakra. Na osnovu dobijenih mikrofotografija može se potvrditi da ekstrakt ruzmarina pruža dobru zaštitu bakra od korozije.

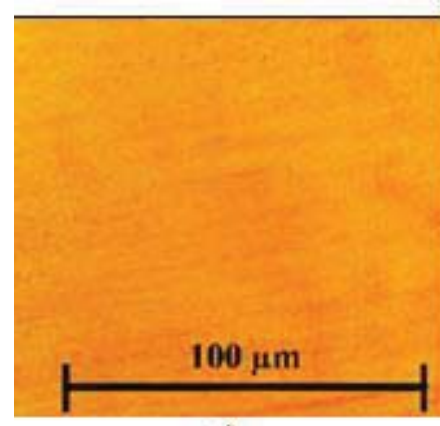

a)

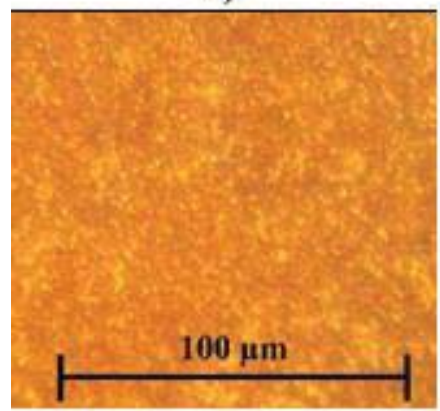

d)

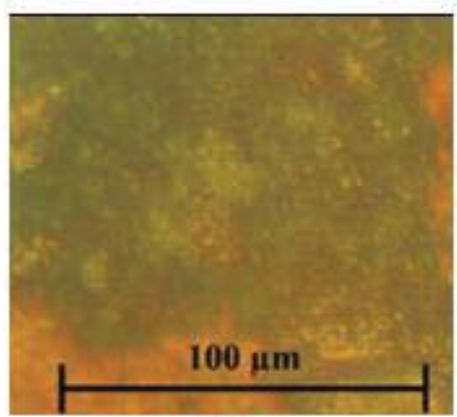

b)

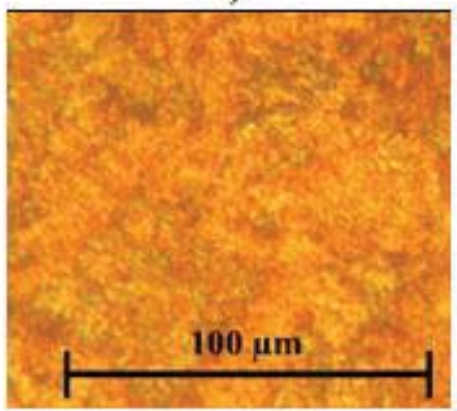

e)

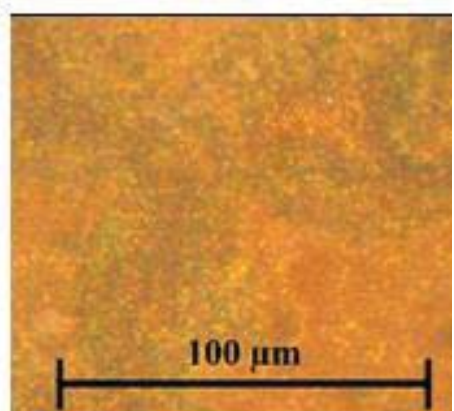

c)

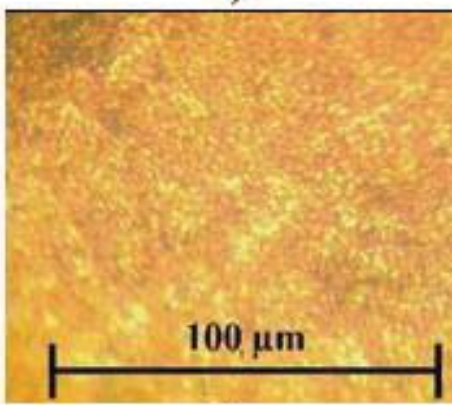

f)

Slika 4 - Mikrofotografije površine bakra pre i nakon potenciostatskog tretiranja na potencijalu od 0,05 V vs. ZKE u trajanju $100 \mathrm{~s}$

Figure 4 - Micrographs of the copper surface after the potentiostatic treatment at $0.05 \mathrm{~V}$ potential vS. SCE,

a) pre potenciostatskog tretiranja,

b) $u 0,5 \mathrm{~mol} / \mathrm{dm}^{3} \mathrm{NaCl}$,

c) u 0,5 mol/dm $\mathrm{m}^{3} \mathrm{NaCl}+1 \mathrm{~mL}$ ekstrakta ruzmarina,

d) u 0,5 mol/ $/ \mathrm{dm}^{3} \mathrm{NaCl}+2 \mathrm{~mL}$ ekstrakta ruzmarina,

e) u 0,5 mol/d $\mathrm{m}^{3} \mathrm{NaCl}+3 \mathrm{~mL}$ ekstrakta ruzmarina,

f) u $0,5 \mathrm{~mol} / \mathrm{dm}^{3} \mathrm{NaCl}+4 \mathrm{~mL}$ ekstrakta ruzmarina

\section{ZAKLJUČAK / CONCLUSION}

Bakar je jedan od veoma značajnih metala za privredu. Lako je obradiv i ima veliku primenu u industriji. Međutim, bakar je podložan koroziji, te je neophodno korišćenje inhibitora korozije kojima bi se usporio ovaj neželjeni proces. Upotreba inhibitora dovodi do formiranja zaštitnog filma na površini bakra, čime se on štiti od oksidacije. Ispitan je veliki broj mogućih inhibitora korozije, među kojima su i zeleni inhibitori.
a) before potentiostatic treatment
b) in $0.5 \mathrm{~mol} / \mathrm{dm}^{3} \mathrm{NaCl}$,
c) in $0.5 \mathrm{~mol} / \mathrm{dm}^{3} \mathrm{NaCl}+1 \mathrm{~mL}$ rosemary exstract,
d) in $0.5 \mathrm{~mol} / \mathrm{dm}^{3} \mathrm{NaCl}+2 \mathrm{~mL}$ rosemary exstract,
e) in $0.5 \mathrm{~mol} / \mathrm{dm}^{3} \mathrm{NaCl}+3 \mathrm{~mL}$ rosemary exstract,
f) in $0.5 \mathrm{~mol} / \mathrm{dm}^{3} \mathrm{NaCl}+4 \mathrm{~mL}$ rosemary exstract

$\mathrm{U}$ ovom radu ispitivan je uticaj ekstrakta ruzmarina, kao potencijalnog ekološkog inhibitora, na koroziju bakra u hloridnoj sredini. Na osnovu izvedenih eksperimenata, mogu se izvesti sledeći zaključci:

- Rezultati merenja potencijala otvorenog kola u rastvoru $0,5 \mathrm{~mol} / \mathrm{dm}^{3} \mathrm{NaCl}$ bez i uz dodatak ekstrakta ruzmarina pokazali su da su vrednosti potencijala otvorenog kola u prisustvu ekstrakta pozitivnije.

- Ispitivanjem elektrohemijskog ponašanja bakra metodom ciklične voltametrije u $0,5 \mathrm{~mol} / \mathrm{dm}^{3} \mathrm{NaCl} u$ prisustvu ekstrakta ruzmarina, pokazalo se da se 
vrednosti jačine struje smanjuju sa povećanjem koncentracije ekstrakta ruzmarina. Ovo znači da se postiže bolji zaštitni efekat ekstrakta ruzmarina sa povećanjem koncentracije ekstrakta ruzmarina.

- Rezultati potenciostatskog merenja pokazuju da se stabilizacija brže dostiže u prisustvu ekstrakta ruzmarina. Vrednosti stacionarne jačine struje u rastvoru $0,5 \mathrm{~mol} / \mathrm{dm}^{3} \mathrm{NaCl}$ u prisustvu ekstrakta ruzmarina su niže u odnosu na stacionarnu vrednost jačine struje bez prisustva ekstrakta. Prisustvo ekstrakta dovodi do formiranja zaštitnog filma na površini bakra, koji usporava proces oksidacije bakra.

- Poređenje mikrofotografija dobijenih nakon potenciostatskog tretiranja bakra u rastvoru 0,5 $\mathrm{mol} / \mathrm{dm}^{3} \mathrm{NaCl}$ bez i u prisustvu ekstrakta ruzmarina pokazuje da je površina bakra značajno oštećena nakon potenciostatskog tretiranja bakra u 0,5 $\mathrm{mol} / \mathrm{dm}^{3} \mathrm{NaCl}$, dok su pri dodatku ekstrakta ruzmarina oštećenja na površini bakra manja jer dolazi do formiranja zaštitnog filma na površini.

Dobijeni rezultati u okviru ovog rada predstavljaju doprinos istraživanjima u oblasti zaštite bakra od korozije primenom netoksičnih prirodnih inhibitora korozije.

\section{Zahvalnica / Acknowledgement}

Istraživanja predstavljena u ovom radu su obavljena uz finansijsku podršku Ministarstva prosvete, nauke i tehnološkog razvoja Republike Srbije, u okviru finansiranja naučno istraživačkog rada na Univerzitetu u Beogradu, Tehničkom fakultetu u Boru, prema ugovoru sa evidencionim brojem 45103-9/2021-14/ 200131.

\section{LITERATURA / REFERENCES}

[1] Coulibaly N. H., Brou Y. S., Diomande G. D., Creus J., Trokourey A. (2018), Int. J. Biol. Chem. Sci., 12(2), 1008-1027.

[2] Emad M., AL-Rasheedi M. (2015), J. Mater. Environ. Sci., 6(1), 201-206.

[3] El-Aziz A., Fouda S., El-Dossoki F.I., El-Nadr H.A., El-Hussein A. (2018), Zaštita Materijala, 59 (3), 422-435.
[4] Fouda A.S., Abdallah Y.M., Elawady G.Y., Ahmed R.M. (2014), J. Adv. Res., 2(11), 517-531.

[5] Fouda A. S., El-Haddad M., Abdallah Y. M. (2015), Int. J. Innov. Res. Sci. Eng. Technol., 2(12), 70737085.

[6] Gudić S., Oguzie E.E., Radonić A., Vrsalović L., Smoljko I., Kliškić M. (2014), Maced. J. Chem. Chem. Eng., 33(1), 13-25.

[7] Hazzazi O.A. (2007), J. Appl. Electrochem., 37, 933-940.

[8] Ivanov S., Grekulović V., Štrbac N., Mitovski A., Marković I. (2020), Ecologica, 27(99), 429-436.

[9] Jokar M., Farahani T. S., Ramezanzadeh B. (2016), J. Taiwan Inst. Chem. Eng ., 63, 436-452.

[10] Kosec T., Milosev I., Pihlar B. (2007), Appl. Surf. Sci., 253, 8863-8873.

[11] Kesavan D., Gopiraman M., Sulochana N. (2012), Chem. Sci. Rev. Lett., 1(1), 1-8.

[12] Milić S. M., Antonijević M. M. (2009), Corros. Sci., 51(1), 28-34.

[13] Milošev I., Pavlinac J., Hodošček M., Lesar A. (2013), J. Serb. Chem. Soc., 78(12), 2069-2086.

[14] Mounir F., El Issami S., Bazzi Lh., Salghi R., Abidi N., Jodeh S., Bazzi L., Chihab Eddine A., J. Mater. Environ. Sci., 6, 8, 2066-2075 pp. 2015.

[15] Petrović Mihajlović M., Antonijević M. (2017), Inhibitori korozije bakra, Monografija, Tehnički fakultet u Boru, Bor, 7-148.

[16] Raja P.B., Sethraman M.G. (2008), Mat. Lett., 62, 113-116.

[17] Radosević J. (2012), Zaštita materijala, 53(4), 313-323.

[18] Rajčić Vujasinović M., Grekulović V., Stević Z., Dragulović D., Dimitrijević S. (2016), Bakar, 41 (2), 35-40.

[19] Stević Z., Rajčić-Vujasinović M. (2007), Hem. Ind., 61(1), 1-6.

[20] Toumiat K., Guibadj A., Taouti M. (2017), Eurasian J. Anal. Chem., 12, 3, 275-214. 